\title{
GENTES Y OFICIOS DE LA LIBRERÍA ESPAÑOLA A MEDIADOS DEL SIGLO XVIII
}

Este trabajo es prolongación del que presentamos en diciembre de 1982 en un coloquio de historiadores sobre "Libro, instrucción y lectura en España, del siglo XVI al Xx" ${ }^{1}$. Explotando una documentación que no tiene equivalente en épocas anteriores, los autos de unas visitas decretadas en 1757 por Juan Curiel, juez de imprentas, en todas las librerías de España, dimos entonces a conocer, según los datos abundantes, aunque probablemente no del todo completos, que pudimos recoger, la implantación geográfica y numérica de las librerías, o, más bien, de los puntos de venta de la librería española, cuya existencia queda documentada en varias series de expedientes del Archivo Histórico Nacional.

Un rápido examen de las cifras obtenidas con tal acopio de datos basta para confirmar y remachar cuanto ha podido decirse de la desastrosa situación de España, en esa época, respecto de los demás países de Europa, y pone de manifiesto un subdesarrollo económico que, en este caso, corresponde evidentemente a un aletargamiento cultural. Según el recuento que logramos hacer reuniendo datos procedentes de dos series distintas de expedientes, que seguramente peca por defecto, existía a mediados del siglo XVIII un comercio de libros con puntos fijos en unas cuarenta ciudades españolas, siendo al respecto las más florecientes Madrid, claro está, Barcelona y Valencia, Valladolid, Sevilla, Zaragoza y Cádiz ${ }^{2}$. Si atendemos a la implantación geográfica, observa-

1 Publicará las Actas el Centre National de la Recherche Scientifique. El grupo de historiadores al que nos adherimos es el C.N.R.S./G.R.E.C.O. 30, del que es responsable Bartolomé Bennassar.

2 Serían unos 60 en Madrid (véase más adelante en qué datos se funda esta conjetura). Las cifras conseguidas en cuanto a las demás ciudades mencionadas son de 27 para Barcelona, 25 para Valencia (donde no se contaron las "paradas"), 16 para Valladolid, 15 para Sevilla, 11 para Zaragoza y 10 para Cádiz. El objetivo de Curiel, al decretar esas visitas, era el cumplimiento de uno de los autos de la "Resolución dictada por el Sr. D. Fernando VI a consulta del Consejo el 27 de noviembre de 1752 ": "Asimismo ningún librero o tratante en libros ni otra alguna persona pueda vender o meter en estos reinos libros ni obras de romance compuestas por los naturales de estos reinos, e impresas fuera de ellos, sin expresa Real licencia, so pena de muerte o perdidamiento 
mos sin sorpresa que la librería alcanza una relativa prosperidad en los puertos del Mediterráneo, en Cádiz, donde se conectaban el tráfico mediterráneo y el atlántico, en las principales ciudades de Andalucía (que no era entidad administrativa, pero poseía fuertes características de otra índole) y de Castilla, siendo un factor muy importante la existencia de una Audiencia, de una Universidad, o de ambas instituciones a la vez. Muy desfavorecidas aparecen las provincias del norte que no suman en su conjunto más que 16 libreros (uno en La Coruña, cinco en Santiago, tres en Oviedo, dos en Bilbao, cuatro en San Sebastián y uno en Pamplona), es decir mucho menos que Barcelona o Valencia, y lo mismo, aproximadamente, que Valladolid. Además se ofrecen a la vista inmensas zonas que son, según nuestro enfoque, verdaderos desiertos culturales: Extremadura, que tiene apenas dos librerías para una extensión mayor que la de Holanda y comparable a la de Suiza; Aragón, donde casi todo queda reconcentrado en Zaragoza, donde hay 11 libreros, mientras que en todo el resto del reino sólo se encuentra uno "de poca consideración" en Huesca, y uno en Calatayud, que no debía de ser de muchísima consideración.

Una comparación global con Francia resulta aplastante, ya que sólo en París había más librerías entonces que en toda España. Pero más pertinente, considerando que la población francesa era entonces tres veces más numerosa que la española, es comparar a España con la mitad meridional de Francia, mucho más pobre que la mitad norte. Y aun así no se encontrará, en cuanto al comercio de libros - por lo que al gran comercio de exportación se refiere-, ninguna ciudad hispana que pueda equipararse con Lyon, por la sencilla razón de que España no exportaba hacia Europa ni alcanzaba a abastecer a sus provincias de ultramar. La gran mayoría de los libros más costosos que necesitaba se hacían en otros países, en Flandes, Francia, Alemania, Italia, Suiza, y a lo largo del siglo XVIII varios centros comerciales entran en encarnizada competencia para apoderarse de los mercados españoles en Europa y América. De este asunto pensamos tratar en ulteriores estudios.

$\mathrm{Al}$ iniciar este artículo hemos preferido hablar en una primera evaluación de puntos de venta en vez de librerías. Muchas veces, efectivamente, hay que distinguir esas dos cosas, y creemos necesario, antes de abordar un tema más amplio, dar por lo menos alguna idea del multiforme comercio de libros e impresos más humildes en la España de aquella época.

A la hora de esbozar una tipología de los individuos que desempe-

de bienes". De hecho, incluso las obras extranjeras traducidas al español e impresas fuera de España quedaron embargadas. Representaban un fuerte porcentaje de las importaciones de libros en español. Conste que ningún librero fue condenado a muerte, a pesar de que abundaron los casos de fraude. Los libreros de Barcelona, algunos de ellos por lo menos, se mostraron reacios y fueron a dar con sus huesos a la cárcel, pero por poco tiempo. 
ñaban algún papel en la difusión comercial del libro en España, bajo el reinado de Fernando VI, vemos primero que se perfilan dos tipos de profesionales que frecuentemente llegan a ocupar una envidiable posición social: el impresor librero, por una parte, y, por otra, el librero "con tienda abierta" y buen surtido. En muchos documentos aparecen las palabras "maestro impresor", y, en efecto, había una jerarquía, desde el aprendiz y el mancebo, hasta el maestro, pasando por los oficiales que a menudo eran regentes. Pero no había un gremio propiamente dicho en Madrid. Existían, eso sí, como es sabido, las antiguas Hermandades. La de los impresores, fundada bajo la advocación de San Juan Ante Portam Latinam (o sea San Juan Evangelista), y la de los libreros, que era la de San Jerónimo.

Luego aparecen los que sólo poseían algún "puesto" (palabra sustituida por la de "paradas" en Valencia). Situábanse estos puestos en la calle, en una plaza, en las gradas de algún convento o una iglesia. En Madrid, por ejemplo, muchos de ellos se agrupaban frente a las gradas o en las mismas gradas de San Felipe (ocho por un lado y ocho por el otro, aproximadamente, en 1757-1758). Es de lamentar que no exista o no se conozca iconografía sobre este mundillo y, más generalmente, sobre las librerías españolas de la época ${ }^{3}$. Ni siquiera disponemos de descripciones que permitan imaginar esos puestos, esas tiendas, si exceptuamos la muy conocida relación de Moldenhawer ${ }^{4}$. Debe por lo tanto el estudioso interrogar con minuciosa atención los pocos textos que se le deparan, y así obtendrá alguna información.

De uno de ellos, un impreso de cuatro páginas en folio sin fecha, pero que, por ciertas expresiones en él contenidas, podría datarse de 1708, extractaremos estas pocas líneas que vienen a continuación de una acalorada defensa de la Hermandad de San Jerónimo de mercaderes de libros, acusada de vender obras prohibidas, opuestas a la fe católica, en un período confuso, el de la Guerra de Sucesión, cuando, según parece, se había relajado la vigilancia de la Inquisición y tenía que intervenir el poder civil:

Y no ay duda nace lo referido de el poco, o ningún reparo que ay en el modo de recibir los dichos Mercaderes de Libros a los que quieren aplicarse a este exercicio, sin informarse primero de la naturaleza, calidad y costumbre $[\ldots]$

${ }^{3}$ Entre las 10,000 estampas que se conservan en el Museo Municipal de Madrid, podría haber algunas en que estuviesen representados los puestos de las gradas de San Felipe. En 1758 se anunció en la Gaceta la obra: "Las Gradas de San Felipe: su Autor el pequeño Piscator el Doct. D. Isidro Ortiz Gallardo, del Gremio y Claustro de la Universidad de Salamanca". No hemos visto este almanaque

4 Véase Émile Gigas, "Un voyageur allemand-danois en Espagne sous le règne de Charles III', RHi (1927), 341-520. Este texto ha sido utilizado por ANTONIO RODRÍGUEZ-MOÑNO en su utilísima Historia de los catálogos de librería españoles (1661-1840). Estudio bibliográfico, Madrid, 1966. 
Respecto de que lo que sucede regularmente, es, que a pocos meses de aver empezado el exercicio, por qualquiera desazón leve, que tienen con el Mercader a quien asisten se despiden, y sin más conocimiento, ni pericia en el Arte, ponen sus caxones, o serones de libros en qualquiera parage público de esta Gorte, no reflexionando el que sean, o no de los géneros prohibidos, por el defecto que tienen en el conocimiento de ellos, y de las órdenes de V.A. que de uno, y otro es de obligación tener noticia qualquiera Mercader, y por lo mismo previene justísimamente V.A. en las advertencias, y mandatos, que se hallan al principio del Expurgatorio General del año pasado de mil setecientos y siete: Que el Mercader que no sepa lo bastante para conocer los Libros prohibidos, y permitidos, se abstenga de este exercicio, y trato, aviendo llegado este desorden de vender Libros a tal extremo, que hasta en las casas de prendas y caxones de Buoneros se hallan de venta Libros sueltos de todos géneros ${ }^{5}$.

De este texto puede deducirse que la profesión de librero (más precisamente: de mercader de libros) no estuvo legal y estrictamente reglamentada en Madrid, ni en otras ciudades, aunque quizá lo estuviera prácticamente en algunas por disposiciones municipales o sencillamente por un derecho consuetudinario que privara más que otro cualquiera. Esto es muy distinto, por cierto, de lo instituido ya desde principios del siglo Xvir en Francia, donde todo estaba reglamentado, y podía saberse en cualquier momento quién era impresor o librero en la ciudad más apartada del reino, cuándo había pasado a ser maestro, qué categoría de libros hacía o vendía, etc. El enorme desnivel de la documentación estatal por lo que toca a la imprenta y la librería, que cualquier estudioso puede comprobar investigando en los archivos de los dos países, refleja y patentiza del modo más concreto el asombroso desgobierno que padecieron la industria y el comercio del libro en España bajo la dinastía de los Habsburgos y también bajo el largo reinado de Felipe $\mathrm{V}$, en que, sin embargo, la política centralizadora instaurada hubiera debido acompañarse de una eficaz administración generadora del saneamiento y fomento tan necesarios. Pero muy poco se hizo durante ese reinado de casi medio siglo, y si los documentos oficiales son mucho más abundantes sólo es desde 1726 en adelante, y además porque casi todos los trámites (para conseguir licencias, privilegios, para pleitear) eran ya de la incumbencia del Consejo de Castilla. A partir de 1726, y a excepción de un legajo que quedó huérfano, no se sabe por qué, en el Archivo General de Simancas, la documentación esencial está reunida en el Archivo Histórico Nacional de Madrid y es abundante. Para el período 1700-1726, es muy poco lo que puede encontrarse. Y por supuesto no existe, en ningún período del antiguo Régimen (ni del siglo $\mathrm{XIX}$ ), cosa alguna que remotamente siquiera pueda compararse con los

${ }^{5}$ Real Academia de la Historia (Madrid). Colección Salazar, T. 48, núm. 32. La T forma parte de la signatura. Este documento está señalado en "Impresores y libreros de Madrid. Documentos referentes a ellos", noticias que dejara Cristóbal Pérez Pastor y que se publicaron en las Memorias de la Real Academia Española, Madrid, 1926. 
espléndidos "États de la librairie" que con sumo cuidado se establecían en Francia, y son ahora un instrumento de trabajo valiosísimo.

En el siglo XvIII, y probablemente antes, según se deduce de varias declaraciones que hemos visto, no tenían obligación los impresores y mercaderes de libros de hacerse miembros de una u otra hermandad, y éstas, por otra parte, acogían no sólo a los impresores y libreros con tienda abierta, sino a los encuadernadores que trabajaban en casa.

Una prueba de la poca, casi nula organización (por el poder) de la librería española a mediados del siglo XVIII (por ceñirnos a unos pocos años, pero lo mismo podría observarse mucho tiempo más tarde), es la imprecisión terminológica que puede notarse en muchísimos documentos de la época. Imposible, por ejemplo, es aclarar de una vez si "mercaderes de libros", o "tratantes" o "negociantes" (a pesar de todo lo que se ha dicho de la diferencia entre "comerciante" y "negociante") son palabras equivalentes de "libreros", porque no pocas veces se usan esos vocablos sucesiva e indiferentemente haciendo referencia a unos mismos individuos, mientras que en otras ocasiones parece situarse el "'mercader" en una posición más elevada que la del simple librero. Por lo demás, cuando el mercader mencionado es mercader de otros géneros, generalmente se dice; pero un "negociante", las más veces, es más que un librero y un mercader. En cualquier caso, hay que acoger con precaución todos estos términos.

Examinando los autos enviados al Consejo de Castilla (de hecho a Curiel) por los Subdelegados de Imprenta, bien pronto se advierte esta imprecisión en los vocablos. Desde Calahorra informan que hay "sólo un comerciante en libros, que más puede intitularse encuadernador de ellos que librero por falta de caudales"'; de Palencia, que no hay más que "un mercader y encuadernador". Otras veces, se habla de "un librero de poca consideración". En Cartagena se señalan "tiendas de libreros [. . .] que son propiamente revendedores por comisión o encargo". En Bilbao y el País Vasco en general, se suele encargar libros a los capitanes de navíos.

Aun limitándose al estudio de la librería madrileña, surgen dificultades de la misma índole cuando hay que representarse lo que podía ser un puesto. ¿A qué se parecería aquello, las más veces, ya que forzoso es admitir que se daba mucha variedad de puntos de venta asíllamados? Cabe imaginar un tenderete con estantes y toldo, una caseta, algo de humilde apariencia, e incluso algo más sencillo, una estera tendida en el suelo y unos libros amontonados o alineados. Pero el Diccionario de Autoridades abre otras perspectivas al consignar que "se toma [la palabra Puesto] también por la tienda o parage donde se vende por menor", y como Tienda "significa también casa, puesto, o parage, donde se venden algunos géneros. . .", quedamos condenados a eterna duda, ya que ni siquiera queda claro si puestos y tiendas eran siempre puntos fijos, semifijos o móviles de venta, cuando no encontramos más datos que una simple denominación. 
Y se complica el asunto con el uso regional de otros vocablos. " $\mathrm{Pa}$ rada" se llama en Valencia el puesto, y no se trata de un local sino de un punto semifijo de venta. Tenemos a la vista el auto de uná visita hecha en Valladolid en 1759, y un recuento (incompleto) de los verdaderos libreros. Hay entonces en la ciudad un impresor (Alonso del Riego), dos maestros libreros, una viuda de maestro librero, siete libreros, y luego cinco "copleros" y una viuda "coplera a los oficios del número de la misma ciudad". Cada "coplero" tiene una tienda. Si consultamos los distintos diccionarios de la Academia para averiguar lo que era un "coplero", vemos que su definición es ésta: "persona que vende coplas, jácaras, romances y otras poesías"'. La palabra "coplero", tan usada en Valladolid, también se empleaba en otras ciudades de España, en Madrid, por ejemplo, pero no aparece en cualquier tipo de documento.

Otra categoría que nos interesa, cuyo papel ha sido singularmente destacado por los eruditos, es la de los buhoneros. Dicha palabra suele ser considerada como el equivalente del término francés "colporteur", muy antiguamente usado para designar a un revendedor ambulante de libritos y otras mercancías baratas. Tanto es así que la expresión "littérature de colportage" viene utilizándose invariablemente para hablar de eso que ha llegado a llamarse "literatura de cordel", tardíamente, ya que en ningún texto del siglo xvin hemos encontrado esta fórmula cuya historia habría que reconstituir. No pretendemos rebatir la opinión según la cual las dos cosas aludidas se confunden, ya que no le faltan fundamentos. Pero quizá no sea inútil recalcar que, si bien los "colporteurs" franceses, desde el siglo XVl, pero sobre todo a partir del Xvil, estaban sometidos a vigilancia y reglamentos ${ }^{6}$, jamás ocurrió lo mismo con los buhoneros de España, por más reconvenciones que les hiciesen los Ayuntamientos. Además, si cualquier diccionario francés define al "colporteur" como revendedor de impresos, aduciendo textos de los siglos XVI, XVII y XVIII en que consta tal acepción, en el Diccionario de Autoridades tan sólo se dice lo siguiente: Buhonero: "el tendero que en una cesta grande, que trae colgada del pescuezo, anda por las calles vendiendo cosas de poco valor: como son agujas, alfileres, dedales, cuchillos, tixeras, y otras semejantes", y en Buhonería: "tienda que muchas veces el mismo dueño la lleva, y otras es portátil [!], que se pone en las esquinas o plazas y se compone de chucherías y baratijas de poca monta. . ." De libros, de pliegos, m palabra. Tampoco aparece alusión alguna a la venta de libros en las páginas que dedica Asensio Gutiérrez a los "colporteurs" franceses que pululaban en España durante el siglo XVII, hasta el punto de convertirse en personillas literarias $^{7}$. Y sin embargo consta la existencia de buhoneros que vendían im-

${ }^{6}$ Henri-Jean Martin, Livre, pouvoirs et société à Paris au xvii ${ }^{\mathrm{e}}$ siècle (1598-1701), Librairie Droz, Genève, 1969, 2 ts., t. 1, p. 356: "Librairies des ponts et colporteurs".

7 Asensio GutiÉrReZ, La France et les français dans la littérature espagnole. Un aspect de la xénophobie en Espagne (1590-1665), Atelier de reproduction des thèses, Université de Lille III, Lille, 1982, pp. 65-70. 
presos en la abundante documentación que hemos podido ver, pero el hecho no es frecuente.

Los distribuidores de impresos baratos son, en parte, sólo en parte, los ciegos, que, desde 1727, a fuerza de solicitudes, representaciones, pleitos con los impresores y libreros, han conseguido que por una Real Resolución los miembros de su cofradía madrileña y sus viudas pudieran vender "por las calles las Gacetas y demás papeles curiosos sin que nadie pueda hacerlo excepto los libreros de profesión y que tengan tienda abierta, los cuales han de poderlo efectuar en sus puestos' '8. Los estudios publicados sobre este tema, el ya antiguo de Cristóbal Espejo y los recientes de Jean-François Botrel, deben leerse con mucha atención siempre que se quiera hablar de la "literatura de cordel". Parece que no pocos eruditos están convencidos de que los ciegos tenían un total monopolio de la venta de pliegos sueltos. Esto es falso, como lo prueba el texto que acabamos de citar y ya había citado Botrel. Ningún librero, jamás, fue desposeído del derecho de vender una mercancía de tan buen despacho como ésta. ¿Qué otra cosa venderían los copleros de Valladolid? ¿En qué tienda o puesto de España faltarían los humildes pliegos? Pero hay más: aun en las calles estaba oficialmente limitado el monopolio de los ciegos de la Hermandad de Nuestra Señora de la Visitación y sus viudas a las "Gacetas, Almanakes, Coplas, Xácaras o Romances, y qualesquiera otros papeles, o libritos de devoción o diversión [. . .] que no excediesen de cuatro hojas". En la misma Real Resolución que hemos citado, se hace referencia (y quizá sea ésta la única a eso que se encuentre en un texto legal y en letra de molde) a otra categoría de pobres revendedores amparados por la ley:

$Y$ que los pobres, que llaman retaceros, y tienen sus puestos fijos en las calles públicas, en los suelos, o paredes, vendan en ellos también romances, relaciones, comedias, estampas, historias y demás papeles y libritos de devoción o diversión que excedan de cuatro hojas y no pasen de cuatro pliegos.

Palabra es ésta, la de retacero, que fue usada en el siglo xvm, que vuelve a aparecer en otros documentos de la época, y que sin embargo no encontró cabida en ningún diccionario. Las más veces se habla de "pobres retaceros", como que eran una categoría de pobres a los que convenía evitar la mendicidad. Así pasaba con los "pobres ciegos", que a veces hacían su agosto y tenían en vida despabiladas viudas que los ayudaban a amasar no despreciables caudales. Una sola vez hemos encontrado la palabra "retacero" asociada a la de buhonero: "En Madrid en dicho día, mes y año, el referido alguacil Matías Vázquez, asistido

8 Este texto impreso está incorporado al leg. 51 634, exp. 8, de la Sección de Consejos del Archivo Histórico Nacional (Madrid). Fue utilizado por Cristóbal Espejo en su estudio: "Pleito entre ciegos e impresores (1680-1755)", RBAM, 2(1925), 206-236; y con más amplia perspectiva por JEAN-FRANÇOIS BOTREL en: "Les aveugles colporteurs d'imprimés en Espagne", MCV, 9 (1973), 417-482, y 10 (1974), 233-271. 
de mí el escribano, pasó al puesto de Francisco Palomino que le tie-

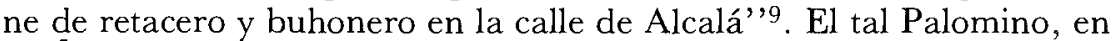
aquel año 1756 ,

tenía tan solamente para su venta dos libritos de la Historia de Carlo Magno impresos en la Imprenta de Dn. Pedro Padilla [. . .], dos ejemplares de Pierres y Magalona, otros dos del Conde Partinuples; otros dos de la Historia de nuestro Redemptor, y dos de Oliberos de Castilla.

Cabe recordar, por fin, aunque es cosa bien conocida de todos los que se han fijado alguna vez en los anuncios de libros de la Gaceta de Madrid, que en la capital y en otras muchas ciudades de España se vendían libros o impresos más humildes en tiendas de todas clases, con joyerías, paños y otros tejidos, en casas de particulares que eran a veces editores de alguna obra propia, en el Ayuntamiento, en el Despacho de la Gaceta y el Mercurio, y a menudo en las porterías de los conventos. Así pasó en la capital con el best-seller español de la primera mitad del siglo XVIII, el Teatro crítico universal de Feijoo, puesto en venta en la portería del convento de San Martín, aunque por supuesto la obra no dejó de formar parte del surtido de las librerías.

Tratemos ahora de vislumbrar, atando ínfimos cabos sueltos, lo que pudiese ser la distribución de textos impresos fuera ya de las ciudades, por caminos y mercados y aldehuelas. Como es asunto sin desbrozar, campo totalmente virgen, por muy reducida que sea nuestra aportación y por más defraudadas que hayan quedado nuestras esperanzas tras huronear en tanto expediente del Archivo Histórico Nacional, podremos según los casos concluir a la inglesa con "negative evidence" o a la española con eso de "algo es algo". Además queremos dejar constancia de que en este tipo de investigación no pasamos de ser historiador novel, con más ilusión que saber.

\section{POR PUEBLOS Y DESPOBLADOS}

Cuando por orden del juez de imprentas Juan Curiel hubo que redactar informes, tras cuidadosa encuesta, sobre todas las librerías de España, nombráronse 39 subdelegados encargados de registrar a fondo el territorio de su jurisdicción, de hacer cumplir lo dispuesto recientemente en Madrid, y de dar cuenta del número de librerías que existiesen en unas regiones a veces de muchísima extensión. Debían entregar los vendedores de libros una declaración firmada, o sea un inventario de los libros "impresos en romance" fuera de España que obraban en su poder. Dicho sea de paso, este cometido no siempre fue cumplido con el debido celo. Los informes remitidos desde Barcelona no propor-

9 Leg. 5 529, exp. 10 (sin foliación seguida), Sección de Consejos del Archivo Histórico Nacional. 
cionan un panorama completo de la librería catalana, y en el País Vasco, en Bilbao señaladamente, se manifestó una chirriante resistencia.

Ahora bien, de vez en cuando, al examinar los informes conservados encontramos alguna fugaz alusión a ciertos individuos que van de feria en feria vendiendo libros o tal cual pliego. Se dice por ejemplo que por Santo Domingo de la Calzada suele pasar un "viandante" con impresos para vender. En Lorca, si no hay librero, estaba hace poco un hombre con este tipo de mercancía, "era de tránsito, que pasaba a las ferias". También en Baeza notifican que no hay en la ciudad librero de profesión, "pero sí con bastante frecuencia transita" un vendedor ambulante. Informan de Mondoñedo que "en esta ciudad y en la comprehensión de su Provincia hay traficantes en libros efectivos, pues sólo los mercaderes de otros géneros suelen tener los que corresponden a enseñar gramática, doctrina cristiana, y algunas devociones'. Hay que tener en cuenta estas pocas pero útiles indicaciones, como también el hecho de que la cartilla (el primer impreso que se distribuía a los niños para que aprendiesen a leer) debía llegar hasta las más apartadas aldeas, para imaginar qué dificultades y qué arbitrios suponía para la alfabetización del pueblo español (que parece haber progresado durante el siglo XVIII) una red distribuidora tan deficiente. Muchas veces, probablemente, en extensas regiones y por largos períodos, se darían escaseces de cartillas como las había de trigo y pan. En este caso, como lo atestiguan varios textos de esa época, los niños aprenderían a leer en pliegos sueltos, en Pierres y Magalona, en Carlo Magno y los doce pares, o en algunos romances. Eso cuando se les daba la oportunidad de recibir una somera instrucción.

En cuanto a la distribución de la cartilla - el impreso más barato y básico de esos tiempos-, cabe recordar, antes de dejar este tema, lo que recientemente decía Jaime Moll:

Hasta el primer cuarto del siglo XIX se mantuvo la vigencia de la cartilla de la catedral de Valladolid, aunque desde fines del siglo anterior los intentos - que no vamos a estudiar - de publicar otras cartillas, basadas en nuevas técnicas pedagógicas, son frecuentes, con algunos éxitos parciales. Y no debemos olvidar las ediciones contrahechas producidas a lo largo de la vigencia del privilegio ni las formas de eludirlo que se practicaron a inicios del mismo, expuestas y prohibidas en la prórroga de 1593 [. . .] Queremos también señalar lo que dice Juan Curiel en su informe sobre el memorial del Cabildo de Valladolid - que solicita, entre otras cosas, el aumento de la tasa de la cartilla - al referirse a la extensión geográfica de su uso: Los tres reinos de la Corona de Aragón tienen sus particulares cartillas, que imprimen con privilegios reales; Vizcaya y la provincia tienen particulares cartillas, pero en Galicia, Asturias y montañas de León y Burgos no se usa de otra cartilla que de las impresas por la Santa Yglesia de Valladolid, y los que se valen de Abecedarios manuscritos usan de su derecho, porque no lo prohibe el privilegio ${ }^{10}$.

$10 \mathrm{El}$ estudio de Moll se publicará en las Actas'del Goloquio del G.R.E.C.O. 30 al que ya hicimos referencia. 
Las últimas palabras de este texto no tienen desperdicio porque aducen la prueba de que, en épocas de escasez de cartillas, podían éstas reproducirse a mano sin infringir ley alguna. Y como se reducía la cartilla a un único pliego que, doblado tres veces, venía a formar un cuadernito en octavo con 16 páginas, era facilísimo copiarla, sacando primero el abecedario, y luego una tabla de multiplicar y las principales oraciones. Debieron de abundar esas copias, pero muy difícil será encontrar hoy día una de ellas. De las impresas incluso, es muy poco lo que se conserva.

Siempre que un investigador se dedique a estudiar la difusión de una obra, cualquiera que sea ésta, deberá tener en cuenta que en siglos en que el libro era generalmente caro, y a veces inasequible por varios motivos aun para quien tuviese dinero, era posible hacer una copia de la obra deseada, que se encargaba a menudo a algún pendolista. Millares de comedias fueron copiadas a mano, y no sólo para uso de cómicos. Y libros a veces voluminosos, que salieron así más caros que el original.

Volviendo ahora a los vendedores de impresos y a las cuestiones de distribución citaremos por segunda y última vez el estudio de Moll:

Las cartillas salían de la imprenta de Valladolid en balones, transportados por arrieros, camino de los distintos centros de distribución, consignados a los corresponsales o encomenderos que tenía el Cabildo de la Catedral, para su posterior venta a las librerías y otros puestos. Cada encomendero surte una zona de mercado y pretende tener el monopolio de su distribución, hecho eludido a veces por algunos libreros que las adquieren directamente en el almacén que el Cabildo de Valladolid tenía en Madrid. Conocemos los nombres de algunos de estos encomenderos de los años cincuenta del siglo XVIIr: Jacobo Dhervé, librero en Sevilla; Antonio Ximénez, mercero en Córdoba; María Ruiz de Vera, viuda, en Granada; Angela Ricarte, viuda, en Cádiz; Joseph Ximénez, en Murcia.

Entiéndase que María Ruiz de Vera era viuda de librero. Ignoramos a qué tipo de comercio se dedicaba Ángela Ricarte en Cádiz, ciudad en que había buenas librerías y posibilidad de adquirir cualquier obra impresa en Europa. Pero como ya se ha visto, no hacía falta ser librero para vender libros. Se encontraban éstos en los sitios más diversos. François Grasset, ginebrino, tras haber estado en España como muchos libreros que iban a la Península a hacer marketing, escribió en 1754 a M. de Malesherbes: "Il n'est pas rare de voir dans des petits villages d'Espagne les libraires vendre dans la même boutique des oeufs, du fromage, etc." 11 Más exacto hubiera sido decir que en las mismas tiendas en que se vendían huevos, queso, etc., podían también a veces encontrarse libros, porque, desde luego, no había aldea que tuviese una librería. En algún informe, y pensamos por más señas en el que se mandó de Almería, se halla esta declaración: "no hay formales librerías"; eso

11 Bibliothèque Nationale (Paris), Département des manuscrits, F. fr. 22 130, fol. 249-252. 
significa muy probablemente que hay comercio de libros, pero que no lo hace un librero propiamente dicho.

$\mathrm{Y}$ de una ciudad a otra, de una aldea a otra, iban y venían arrieros y carretas, procedentes de Bilbao, de Barcelona, de Valencia y Alicante, caminando frecuentemente hacia Madrid. El itinerario de Alicante a la capital era el más recomendado por los libreros madrileños a sus abastecedores extranjeros. En Bayona, que había de conseguir el estatuto de puerto franco en 1784, hubo total libertad durante todo el siglo para comprar cualquier mercancía extranjera, y no escaseaban los libros entre dichas mercancías. Numerosos arrieros llegaban allá, viniendo a veces desde Barcelona, y cada uno podía cargar hasta 16 arrobas, que son aproximadamente 185 kilos. En la famosa gabarra de Behobia, podía entrar cualquier cargamento en España, por lo menos hasta 1752, año en que el gobierno español trató de controlar lo que se introducía de este modo en el reino. Como todo navío que había atracado en Bilbao podía hacerlo después sin control en cualquier puerto de España, trataban los agentes de la Inquisición de registrar los cargamentos, y eran innumerables los conflictos con el Consulado de Bilbao ${ }^{12}$. Grandes cantidades de libros fueron pasando de esta manera de Francia al País Vasco, desde allí, por vía marítima, a Cádiz y Sevilla. No pocos balones se encaminaban sigilosamente del País Vasco a Navarra, y de allí a toda España si lograban burlar la vigilancia de las aduanas. Incluso en Madrid se metían muchos libros clandestinamente ya que los negociantes extranjeros y sus clientes mucho sabían de trazas y ardides, encubriendo obras prohibidas con títulos anodinos, disimulando los pliegos de los libros, que generalmente llegaban sin encuadernar, dentro de otros pliegos, e imaginando otras muchas artimañas.

No podemos dejar de traer a colación otro tipo de librero, aunque bien pudo representar éste un caso aislado. Consultando la amplia documentación en que se fundamenta este estudio, leímos una declaración que avivó nuestra curiosidad, hecha en Carmona acerca de unos libros recién adquiridos. Decía textualmente: "el dueño de los citados libros es un extranjero que va de pueblo en pueblo con una librería". El misterio del librero andante ${ }^{13}$ no tardó en aclararse. Se trataba de un tal Ramón Gravier, que, con una carreta, iba recorriendo extensas comarcas de Andalucía, vendiendo libros, incluso gruesos volúmenes importados, y también pliegos sueltos. Ese francés tenía homólogos en su país natal, y a uno de ellos se ha dedicado un estudio de rumboso título: "Noël Gille dit la Pistole, marchand forain libraire roulant par la France"'14. Tenemos la convicción de que ese Gravier era uno de

12 Debemos estos datos a Mme. Lomné, que hace su tesis de doctorado sobre el País Vasco en el siglo XVIII.

13 No hay apenas humorismo en esta fórmula. Se usaba durante el Siglo de Oro para designar a los revendedores ambulantes. Véase PÉrez PASTOR, Bibliografía madrileña, t. 1, Introducción, pp. xlii y xliv.

I4 Art. de A. Sauvy, publicado en el BBF, 1967, 177-190. 
esos "colporteurs" oriundos del Delfinado, de la región de Briançon más precisamente, que de sus nieves natales salían a vender libros por todo el sur de Francia, por las penínsulas italiana e ibérica, logrando poner tienda a veces en grandes ciudades y tejiendo redes comerciales que podían llegar hasta América. Ya citamos en otra ocasión unas líneas del memorial dirigido por François Grasset a M. de Malsherbes, director general de la Librería en Francia:

Le commerce de la librairie en Espagne et au Portugal, de même que celui de beaucoup de villes d'Italie, est presque tout entre les mains des français, tous sortis d'un village situé dans une vallée du Briançonnais, dans le Dauphiné. Ces gens, actifs, laborieux et extrêmement sobres, passent successivement en Espagne et s'allient presque toujours entre eux. Leurs finesses dans le commerce leur a fait donner le nom de Bizouards. Ils donnent à ce nom une singulière étymologie, ils prétendent que $B$ is signifie deux et que zouard, dans la langue de leur pays, veut dire honnête homme et que, par conséquent, le mot de Bizouard veut dire deux fois honnête homme. Quoiqu'il en soit de cette rare et singulière étymologie, il n'est pas moins certain que non seulement le commerce de la librairie est dans leurs mains, mais encore ceux des cartes de géographie, d'estampes, horlogeries, toiles, indiennes, bas, bonnets, etc.

Comentando estas declaraciones, ya apuntó Georges Bonnant, autor de varios excelentes trabajos sobre las exportaciones de libros desde Ginebra a Portugal y España:

En effet, les libraires Borel, Martin, Bertrand, Aillaud, Rey, Orcel, Dubeux et Semion, à Lisbonne, et Jacques Antoine Orcel à Coïmbre, sont originaires du Briançonnais. Quant au mot de bizouard, c'est une expression dialectale des Alpes dauphinoises qui signifie colporteur ${ }^{15}$.

Hemos podido advertir al exponer nuestra primera presentación general de la librería española a mediados del siglo xvil, que lo consignado por François Grasset suscitaba escepticismos entre los oyentes risueños. No obstante, lo que ya hemos logrado averiguar acerca de los libreros franceses de España en aquel entonces, y de sus orígenes, viene dando toda la razón del mundo al librero ginebrino, ya que los Barthélémy de Madrid, como también los Orcel, los Bonnardel de Barcelona y los de Cádiz, no sólo eran oriundos del mismo valle, sino que habían nacido en el mismo pueblecito: Monestier de Briançon, hoy: Monêtierles-bains. Lo único que es falso, en el memorial de Grasset, es eso de que estuviese casi todo el comercio de la librería española en manos de franceses. Pero de los libreros franceses trataremos en un estudio ulterior.

Volvamos ahora, para esbozar un rápido panorama, a los libreros

15 G. Bonnant, "Les libraires du Portugal au xviII ${ }^{\mathrm{e}}$ siècle vus à travers leurs relations d'affaires avec leurs fournisseurs de Genève, Lausanne et Neuchâtel" , $A B P$, 6 (1960), 7-8. 
de verdad y por consiguiente a las ciudades. Fuerza es que hablemos tan sólo de Madrid, porque si bien no carecemos de datos sobre otras ciudades, en la capital fue donde pudimos localizar y explotar más fuentes documentales.

\section{ASPECTOS DE LA LIBRERÍA MADRILEÑA}

No se ha hecho ningún estudio global sobre los libreros de Madrid (ni de otra ciudad) en el siglo XVIII ${ }^{16}$. El trabajo ya antiguo de Emilio Cotarelo no es más que una evocación amena y castiza de aquel mundo, y no está muy bien documentado. No se entiende cómo pudo considerar un hombre tan docto que las "bibliografías mensuales" del $M e$ morial erudito eran "la mejor fuente para hacer el cómputo" que él se proponía, eligiendo "un año cualquiera, por ejemplo, el de 1784"'17. Los títulos aparecidos en dicho año (y no en su totalidad) están recogidos en la primera obra que se publicó en España con pretensiones verdaderamente bibliográficas, la Biblioteca periódica anual para utilidad de los libreros y literatos (Madrid, 1784-1791). Al final de cada volumen de dicha Biblioteca, se añadió una lista de los libreros, con sus respectivas señas, que como fuente de información, para la época considerada, supera a todas luces las noticias del Memorial erudito y de la Gaceta de Madrid, del Diario y de cuantos periódicos se conocen. En esta lista se mencionan no sólo libreros, sino puntos de venta como el Despacho Real de la Gaceta y la Imprenta del Consejo de Indias. Vienen nombrados en ella 60 libreros y señalados los dos establecimientos citados. Cotarelo, ateniéndose a las noticias del Memorial, precisamente para el primer año en que convenía descartarlas o no limitarse a ellas, hizo un recuento de cincuenta libreros tan sólo. Pero por eso mismo, más interés tiene todavía el comentario que le merecen sus cifras erróneas sobre la situación del Madrid de las luces respecto del Madrid de su tiempo: "Cincuenta librerías, que todas vivían y vivieron muchos años, dan una idea muy lisonjera del estado de instrucción de nuestros bisabuelos del siglo XVIII". Y ya había estampado al iniciar su exposición en forma de paseo por las calles y plazas de la Villa y Corte: "Madrid, que hace siglo y medio apenas contaría la cuarta parte de habitantes que en la actualidad, tenía un número de librerías proporcionalmente mayor que hoy", Una observación de esta índole no debe caer en saco roto, aunque hay que tener mucho cuidado al comparar realidades tan alejadas en el tiem-

16 En el libro de Iris M. Zavala, Clandestinidad y libertinaje eruditos en los albores del siglo xviii, Ariel, Barcelona, 1978, es muy notable la preocupación de la autora por estudiar las infraestructuras de la vida intelectual. Las páginas que dedica a las "Penas y quebrantos de libros y libreros" (pp. 343 ss.), basadas en la misma documentación que manejamos, son de singular interés.

17 "Libreros de Madrid a fines del siglo XVIII", estudio recogido en FeLIPE BeLTRÁN, El libro y la imprenta, Madrid, 1931. 
po. En el siglo XVIII, están generalmente compenetrados los comercios del libro antiguo y del libro nuevo. En tiempos de Cotarelo, tendían a separarse por completo los dos negocios, que ya procuraba distinguir, desde 1863, la estadística administrativa. Lo que indudablemente resalta de un prudente cotejo de cifras y fechas es que si en España, a mediados del siglo XVIII, consta la existencia de unas 180 librerías en las distintas provincias, y de unas 60 en Madrid, cifras que más bien pueden pecar por defecto que por exceso, el incremento en este ramo durante el siglo posterior estuvo muy lejos de corresponder al aumento de la población. En 1863, sólo se empadronaron 90 libreros de viejo, y 255 con tiendas de libros nuevos ${ }^{18}$.

Volviendo a los años 1757-1758, estrecha pero decisiva coyuntura a la que queremos atenernos, los datos más asequibles de los que disponemos sobre la librería madrileña son los que proporciona la Gaceta de Madrid con sus anuncios comerciales. Los que puede suministrar el Diario curioso, erudito y comercial, público y económico que tuvo su aparición el 2 de febrero de 1758, ya utilizados en una obrita de Francisco Vindel, resultan menos abundantes por lo que se refiere al tema nuestro. Treinta y cuatro librerías y puestos contó Vindel (clasificados por calles y plazas, con el nombre de cada dueño), mientras que son cerca de cuarenta los que aparecen en los anuncios de la Gaceta $^{19}$. No puede redondearse esa cifra porque no siempre está especificada la calidad del anunciante. Además hay que tener en cuenta que no todos los vendedores de libros (fuesen impresores, libreros con tienda abierta, dueños tan sólo de algún puesto o meros encuadernadores, $u$ oficiales que habían reñido con su amo) amén de los retaceros y demás gente humilde de que ya hablamos, publicaban anuncios en la Gaceta. Quizá fuese porque, hasta el 12 de enero de 1762 , quien quisiese tener un anuncio publicado en la $\mathrm{Ga}$ ceta tenía que contribuir con un ejemplar, y los libros eran caros. Como de todos modos la publicidad podía beneficiar a quien no anunciara, es de suponer que no pocos dejaban que anunciaran los demás. Téngase también en cuenta que había impresores y libreros, conocidos y acomodados, que durante años no anunciaban en la Gaceta ningún libro: en 1757 y 1758 no aparecen, por ejemplo, los nombres de Ibarra ni de Alonso Padilla, muy representativos por cierto de dos sucesivas generaciones de editores, libreros e impresores.

Poniendo atención en los anuncios de la Gaceta de Madrid, se notan anomalías (y valga el eufemismo) que serán todo lo pintorescas que se quiera y harán sonreir cuando menos, pero que revelan o permiten adivinar una miseria, un abandono nada risibles. No poca sorpresa habrá de causar, a quien tenga conocimiento de lo que era entonces el comercio de libros en París o en Londres, algunos hechos como los que vamos

18 Véase J.-F. Botrel, Pour une histoire littéraire de l'Espagne, 1868-1914, tesis de doctorado de Estado, todavía inédita, defendida en 1981, t. 2, caps. 3 y 4.

19 F. VINDEL, El Madrid de hace 200 años (1758), Madrid, 1958. 
a consignar rápidamente. Si se señaló la portería del convento de San Martín como primer punto de venta del Teatro crítico universal de Feijoo en 1726, el 21 de febrero se anunció: "Libro nuevo: Historia del famoso predicador Fr. Gerundio de Campazas. Tomo primero: su autor D. Francisco Lobón de Salazar, presbytero; se hallará en casa de Morales, mercader de paños en los Portales de Guadalajara, y en Zaragoza, en la Librería de los Herederos de Mendoza, calle del Coso". Un poco antes, en el año de 1757, apareció lo siguiente: "Noticias de la otra vida y de (sic) estado de las almas en el otro mundo del R.P. Lucas Pinelli, jesuita. Este libro y otros del mismo autor se hallarán en casa de Joseph Terroba, Mercader de Lonja calle de Atocha, y en el Almacén de Azúcar, frente del Cementerio de Santa Cruz'. El tal Terroba era mercader de sedas, según se declara en otros anuncios, y tanto en su casa como en el almacén de azúcar que estaba enfrente del Cementerio de Santa Cruz se despachaban nada menos que las Obras, en costosa edición de muchos volúmenes, de fray Luis de Granada, que en pocas bibliotecas españolas faltaban entonces. El libro intitulado Vida de Jesu Cristo de Fr. Fernando de Valverde se vendía en la portería de San Felipe el Real "y en Casa de Pedro Libarona, Mercader de Fierro, calle de Toledo". En el Diario encontramos también detalles interesantes en avisos que son como los anuncios por palabras de la época:

Se vende el juego completo del Diccionario de la Lengua Castellana, en 6 tomos, compuesto por los señores de la Real Academia de la Lengua, el que le dejará ver, y se dará con mucha equidad en la botica de la Calle de la Salud (10-VI-1758);

y este otro:

En la Calle de Santa María, entrando por la de el León, a mano derecha, primera puerta, quarto segundo, se venden 70 comedias de Calderón, 27 de Moreto, como unas 150 de Candamo, Zamora, Cañizares, Diamante, Rojas, Solís, y otros varios ingenios: y también una porción de Saynetes y Entremeses exquisitos; se dará con alguna equidad (31-VII-1758).

Puede notarse que también con alguna equidad clasificó el anunciante a los dramaturgos de cuyas obras se deshacía.

Si los libreros, con tienda abierta, con sólo puesto, con tienda y puesto a la vez, y además los impresores que vendían libros, cuyos nombres se mencionan en la Gaceta, son apenas unos 40 individuos, sabemos por otra fuente que los que total o parcialmente vivían de la fabricación y comercio de libros en Madrid eran muchísimo más numerosos. En el año 1757 se realiza precisamente el primer catastro de la Villa y Corte, que bajo dos categorías principales (Arte de impresores y Arte de libreros) hace un censo de 7 impresores de estampa, 2 fundidores de letra, 5 oficiales que regentan imprentas de viudas, 13 impresores que tienen 
aprendices por su cuenta, 71 oficiales con un jornal de 8 reales, 64 oficiales con un jornal de 7 reales, 6 oficiales con un jornal de 6 reales, 18 aprendices que ganan 4 reales. En total para el "Arte de impresores": 186 individuos, entre los cuales hay 141 oficiales. El "Arte de libreros", por otra parte, está integrado por 29 comerciantes en libros, 10 libreros, 31 oficiales "que hacen libros en sus casas", "copleros con puesto" (cuyo número no está indicado), 48 oficiales, 10 mancebos y 49 aprendices. En total: 177 individuos, y si se suman las dos categorías: 363 , entre los cuales los oficiales son 189 , y si se añaden los que hacen libros en sus casas (es decir los encuadernadores) se llega a la cifra de 220 trabajadores asalariados, a los que cabe agregar 77 aprendices y mancebos. Obsérvese que los "copleros con puesto" (que serán nuestros retaceros, en principio) no están empadronados. Esas cifras son las que dan la idea más exacta de lo que era el proletariado del libro en el Madrid de aquel entonces ${ }^{20}$.

La labor más penosa era la de los oficiales tipógrafos que, como en los demás países de Europa, se obligaban a tirar 1,500 pliegos en una jornada. Muy oportunamente recordaba Jaime Moll en el estudio que ya hemos citado que el Diccionario de Autoridades dice lo siguiente en uno de los apartados del artículo Jornada: "Se llama en la Imprenta lo que puede tirar la prensa en un día, que regularmente son mil y quinientos pliegos. L. Diurnus labor typographicus". Y añadía Moll: "1,500 pliegos (o sea 3,000 caras impresas, que se traducen en 6,000 golpes de prensa". Ese era el ritmo de trabajo de cualquier oficial tipógrafo en Europa. Uno de ellos, muy famoso por sus escandalosos escritos, Nicolas Restif de la Bretonne, dejó constancia de lo que había sido esa vida de oficial, de la costumbre de acabar la jornada con las manos sangrando. Como no existió en España una gran concentración de talleres, nunca hubo huelgas ni disturbios como los que sacudieron a Lyon en los tiempos de su esplendor. No parecen haber sido los trabajadores del libro en España gente reivindicativa. Se les echaba en cara su poca afición al trabajo y al estudio, y ese "guardar los lunes" que denunciaría Campomanes invocando el ejemplo de la laboriosidad alemana:

Las imprentas he visto yo muchas veces, sin que lo puedan remediar los impresores, ni aun agasajando a sus gentes, desamparadas los lunes de oficiales, como de los aprendices. Contado este día de la semana, con los de fiesta, hacen un menoscabo considerable a la industria popular; y lo mismo sucede si en los días festivos, en que oyendo misa es lícito trabajar, se dispensan de sus tareas los artesanos, y se entregan al ocio y a las diversiones ${ }^{21}$.

20 A. Matilla Tascón, "El primer catastro de la Villa de Madrid", RABM, 69 (1961), p. 492.

21 P. DE Campomanes, Discurso sobre la educación popular, ed. preparada por F. Aguilar Piñal, Madrid, Editora Nacional, 1978, p. 105. 
También se quejaban unos impresores de la poca instrucción de los que se dedicaban al arte de imprenta. Y desde luego no escasean los textos en que se denuncian las malas costumbres de los oficiales, que se dedicaban al juego y bebían más de la cuenta. Pero esto no es propiamente español. En todas partes se decía lo mismo, y nada tiene de extraño que un oficial que llevaba tan perra vida necesitara emborracharse siempre que se lo permitiera su jornal. Aunque los salarios de los tipógrafos españoles eran más elevados que los que pagaban en otras partes, en que a más riqueza correspondía más explotación de los trabajadores, no había oficial que pudiera mantener una familia, varios hijos, con 7 reales de jornal. En períodos de alza de precios sobre los productos alimenticios (fundamentalmente el pan), condenado estaba, a no ser que trabajara también su mujer, a la necesidad, al hambre ${ }^{22}$.

Si Madrid era pobre, y si era pobre casi toda España ¿quiénes eran entonces los que conseguían medrar, alcanzar una honrada medianía o llegar a edificar una auténtica fortuna con el comercio de libros o su industria?

En el año de 1757, al que tratamos de ceñir este estudio, y que fue un año de relativo desahogo para el pueblo de Madrid, ya que el pan estuvo al precio más bajo, baratura que nunca jamás volvería a verse, un impresor que se había establecido en la Corte apenas cuatro años antes, conocía disgustos y sinsabores por una edición del Catón cristiano hecha sin licencia, pero también sin intención de infringir la ley. A pesar de la inocencia evidente de este hombre, se había llegado incluso a dictar contra él auto de prisión en 1756. El 23 de marzo de este año, el atribulado impresor, viudo de su primera mujer, doña Manuela del Castillo, había casado en segundas nupcias con doña Manuela Contero, firmando una carta de pago y recibo de dote. Este documento, que quería publicar Ángel González Palencia pero que nunca logró sacar a luz, nos informa de lo que era entonces el "Capital de los bienes de Joaquín Ibarra"'23. El material de su taller, con seis prensas, "tres nuevas y tres andadas" valuadas en 7,200 reales, cuarenta pares de cajas de letras, cien galeras, 76 tablas de papel y de formas, 44 chivaletes, una prensa de empaquetar, una prensa para cargar papel, fundiciones de peticano, parangona, etc., importa en conjunto 30,894 reales. La ropa, los muebles, todo lo demás hace ascender el "capital" a 32,473 reales. El taller, pues, muy bien equipado y que no tiene equivalente en ninguna imprenta de provincia, lo es casi todo. El objeto más caro que hay en el mobiliario de Ibarra es un reloj que vale 240 reales. Es Ibarra un hombre acomodado, y es dueño de sus instrumentos de trabajo, costosa inversión que con tal artista y en semejante coyuntura hará riqueza y singular fama. Huelga exponer largamente que una imprenta con seis

22 Véase Jacques Soubeyroux, Paupérisme et rapports sociaux à Madrid au xviii siè- $^{-}$ ele, Atelier de reproduction des thèses, Université de Lille III, Lille, 1978, pp. 75 ss.

23 Archivo Histórico de Protocolos de Madrid, prot. 17 950, ff. 171-174. 
prensas necesita la fuerza de trabajo de unos doce oficiales que las manejen, si es que todas funcionan simultáneamente, de cajistas, correctores (a no ser que el mismo autor de la obra lo sea, o el impresor), mancebos, aprendices quizás. Si tiene poca ropa y no muchos muebles, es Ibarra un patrono.

En el año de 1757, el 11 de diciembre, y a consecuencia de la postura autoritaria del juez de imprenta Juan Curiel, que con inquebrantable tesón se ha propuesto sanear el comercio de libros en España y hacer por fin acatar las leyes a quienes el incumplimiento y el fraude parecen ser la cosa más natural del mundo, se reúnen y comparecen los mercaderes de libros, libreros y encuadernadores en el convento de Santo Tomás, ante el escribano Felipe de Castilblanque para dar su "poder completo para la observación de las nuevas ordenanzas". Algún amparo legal necesita esa gente sobresaltada por las órdenes de Curiel de imponer a rajatabla lo nuevamente dispuesto. Más de cien firmas figuran al final de este documento, y, entre las últimas, una que es muy legible: la de Antonio Sancha, que sólo es todavía un mero encuadernador, de esos que trabajan en su propia casa. Diez años antes, en 1747, firmó una declaración de pobre. Pero Sancha no es entonces un pelagatos. Ha casado oportunamente con doña Gertrudis Sanz, que es una de las hermanas de Antonio Sanz, el rey de la librería madrileña, y por consiguiente española, en esta época.

Ningún librero más rico, seguramente, que Antonio Sanz de Ureña, natural de la villa de Cuéllar, hijo de Francisco Sanz y de doña Mariana de Ureña, vecinos y naturales de la misma villa en la parroquia de San Esteban, sobrino de otro Francisco Sanz, impresor del Rey, cuyo cargo y bienes heredara, impresor además del Consejo, editor y librero con tienda abierta en la plazuela de la calle de la Paz. En el testamento de este ricachón, fechado el 5 de abril de 1777, se lee que era dueño de muchas casas en Madrid, que gozaba de varias capellanías, era accionista de la Real Compañía Guipuzcoana de Caracas así como de la Real Compañía de la Habana, miembro de la junta directiva de la Compañía de Impresores y Libreros del Reino fundada en 1763, pero con antecedentes desde 1758. Curiosamente este opulento impresor, editor y librero sólo imprimió un catálogo de sus producciones, del que no tuvo noticia Antonio Rodríguez-Moñino, y en que casi sólo se ofrecen comedias, "historias", impresos de poco valor, como hubiese sido el caso de cualquier modesto impresor especializado en la edición de pliegos baratos $^{24}$. Una de las voluntades expresadas por Antonio Sanz en su testamento no puede más que llamar la atención y suscitar alguna perplejidad: es la prohibición de enajenar unas capellanías "y de que se quite y borre el rótulo que tiene en el dintel de la puerta, que dice Imprenta de Sanz, para que subsista el nombre de mi familia, que de dos-

24 El catálogo está incorporado en el leg. 5 529, exp. 10, de la Sección de Consejos del Archivo Histórico Nacional. 
cientos años a esta parte ha estado en dicha calle de la Paz''. No se conoce ningún impresor madrileño que lleve dicho apellido en el siglo XVI. La historia de esta familia de tipógrafos, con los documentos que, hoy por hoy, tenemos a la vista, no se remonta más allá de los años de 1670 . Es posible que anteriormente hayan sido unos Sanz oficiales del arte de impresores.

Otro librero que, a mediados del siglo xviII, ha hecho fortuna es Pedro Joseph Alonso y Padilla, "curioso tipo bibliopolesco, hombre enfatuado y henchido de presunción, aunque de singular gusto y gran conocedor de la literatura clásica" a juicio de Antonio Rodríguez-Moñino. En efecto solía anunciar Alonso Padilla sus producciones y ponderar sus múltiples capacidades con hiperbólicas expresiones, dándoselas de hombre culto que aleccionar podía a cualquiera, y hacía a un muy selecto público el favor de proporcionarle los libros más exquisitos y raros. De hecho, fue el librero más "castizo" de su tiempo, manifestó gran afición a la literatura española del Siglo de Oro, que como impresor, editor sobre todo, ilustró cuanto pudo, aunque muchos libros suyos y singularmente sus ediciones del Quijote son de las más ruines que hemos visto. Sus hojitas de publicidad que solía difundir, insertándolas en sus ediciones, son muy conocidas de los especialistas que en varias ocasiones han destacado su labor editorial. Ahora bien, no podían faltar en su tienda obras extranjeras, esas novedades que pedían los clientes adinerados. Durante muchos años tuvo su imprenta en la calle de Santo Tomás. Fallecería en 1771, soltero y sin herederos, razón por la cual pasó todo su surtido a la Compañía de Impresores y Libreros del Reino. Los numerosos libros que dejó, y cuyo inventario hemos podido ver gracias a la gentileza de doña María Brey, se valuaron en 125,727 reales.

Pero el hombre más sagaz, activo y afortunado que se abrió camino en la librería española de esa época fue, en nuestro sentir, Francisco Manuel de Mena. Empezó a publicar anuncios en la Gaceta en 1733, teniendo ya tienda de librero en la calle de Toledo. Muy pronto se percató de que el mercado de libros antiguos podía proporcionarle cuantiosos beneficios y anduvo comprando bibliotecas de particulares o de conventos, cada vez más ricas, en Madrid y por toda su provincia. En cuanto olfateaba alguna sabrosa presa, salía de su casa-tienda de la calle de Toledo y caminaba leguas y leguas montado en su mula y con buenos serones. En la obra de Emilio Cotarelo y Mori ${ }^{25}$, se dan a conocer los provechosos tratos que tuvo Mena con la Biblioteca Real, y las cantidades que se le entregaron por los libros raros que vendía son muy importantes. Buenos clientes eran también los eruditos y bibliófilos de ese tiempo. Para ellos y la Biblioteca Real llegó Mena a rastrillar hasta el vecino reino de Portugal donde tenía dos mozos ojeadores. Se conoce un catálogo suyo de 1742, del que habla Rodríguez-Moñino. Consta de 155 páginas en $8^{\circ}$ nada menos. Otro catálogo muy interesante es

25 Emilio Cotarelo y Mori, Iriarte y su época, p. 19, nota 2. 
el que hizo después de adquirir la "librería"'de Andrés González de Barcia (432 páginas en $8^{\circ}$ ) en 1745 . En el mismo año publicó un tercer catálogo, de 228 páginas en $8^{\circ}$, en cuya advertencia puede leerse que Mena tiene otra tienda en la calle de las Carretas, mientras que en la portada sigue indicando que los libros "se hallan venales en la calle de Toledo, frente de la portería de la Concepción Gerónima, quarto segundo". Tras los años de aprendizaje y ya con buenos caudales, alquiló en efecto Francisco Manuel de Mena una nueva tienda que había sido de otro librero, José Antonio Pimentel, en la calle de las Carretas, como se decía entonces. El alquiler elevado (2,000 reales) hace suponer que este local era de los mejores. Además su situación a unos pasos de la Puerta del Sol, en la que, habiendo abandonado los alrededores de la Plaza Mayor, se concentraba el comercio de libros (y en la calle de la Montera, y en la carrera de San Jerónimo) era realmente inmejorable.

A mediados de siglo, Mena era un hombre rico y con influencias. Se había relacionado con los hermanos Cramer (que habían estado en Madrid en 1750), con los de Tournes, ginebrinos también, aunque instalados en Lyon para poder con más facilidad comerciar con toda la Europa meridional. Además, y por si fuera poco, en 1752 Mena había adquirido la concesión de la impresión y venta de la Gaceta de Madrid, luego del Mercurio Histórico y Político, y años más tarde lograría también la de la Guia de Forasteros que disfrutara hasta entonces Antonio Sanz.

Francisco Manuel de Mena debió de ser apasionado y violento. Estuvo a matar con el juez de imprentas Juan Curiel ${ }^{26}$, que prohibía la introducción en el reino de libros en español impresos fuera de España, privando de pingües beneficios a los importadores (y no había librero de categoría que no lo fuera). Mena fue también uno de los 33 libreros que protestaron contra los autos del juez de imprentas, desde luego, y quien más ladró. Mucho habría que contar de este librero, editor e impresor, pero baste decir, de momento, que en el año 1757, según declaración del interesado, el surtido de Mena se componía de unos 30,000 libros. La lista que entregó de obras impresas en español fuera de España es a todas luces muy incompleta. Son proporcionalmente demasiado numerosas las ediciones antiguas que constan en ella, y las modernas pocas, lo cual no deja de sorprender cuando se recuerda que negociaba este insigne mercader con los Cramer y de Tournes. Ni trataba de disimular su fullería. A su muerte, ocurrida en 1780, dejaría Francisco Manuel de Mena una fortuna valuada en 530,000 reales ${ }^{27}$.

Frente a un Sanz, a un Alonso Padilla, a un Mena, sólo cabe colocar a los libreros franceses que se habían enriquecido sobre todo gracias a sus tratos con Lyon y París: los Barthélemy, los Orcel, que tenían

26 Véase la carta citada en nuestro trabajo anterior. El original está en la Bibliothèque Nationale de Paris, Département des Manuscrits, F. fr., 22,130, f. 258.

27 Archivo Histórico de Protocolos de Madrid, prot. 18,188. 
sus tiendas en la Puerta del Sol, frente a la fuente, y en la calle de la Montera, respectivamente, o el italiano Angel Corradi.

De los libreros de otras ciudades, como Barcelona, donde prosperan los Piferrer, Valencia, que tiene excelentes impresores y mercaderes de libros, Cádiz, Sevilla y las demás de Andalucía, no podemos tratar en este trabajo de extensión limitada.

En conclusión queremos destacar que el breve período que hemos enfocado y que corresponde al final del reinado de Fernando VI, fue un momento determinante para la librería española. A decir verdad, la época de Fernando VI vio nacer más proyectos y realizarse más reformas, no sólo por lo que a la cultura y al fomento se refiere, que la de Felipe V. En los años 50 del siglo se perfilan hombres y designios verdaderamente nuevos. En el ramo que hemos evocado, la librería, la política de Curiel, sensata y firme, de cuño colbertista, surtió excelentes efectos, aunque no llegó a imponerse totalmente. Ante la obligación de sustituir a sus abastecedores extranjeros para la impresión de obras escritas en castellano (y conste que esta categoría de obras no era mayoritaria entre las que se traían de fuera), tuvieron que operar los profesionales del libro una reconversión, pasando a ser impresores o editores vinculados a unos talleres nacionales. En dos o tres decenios, mejoraron notablemente la librería, la imprenta y en general la cultura de la nación.

Compárese el estado de la librería, tal como lo hemos esbozado, en lo que sólo era un rápido escarceo, con el de los años 80 . Saltan a la vista los progresos. También hay que fijarse en unas permanencias, que son lo profundo de la historia. En el año 1757 existe una Europa de las Luces y se está publicando L'Encyclopédie. España no pertenece a esa Europa. Sólo se ha incorporado, gracias a unos pocos hombres, a lo que se llamó "L'Europe des savants". Verdad es que no hubo "Philosophie" en España, sino Ilustración, cosa a la vez parecida y muy distinta, ya que las Luces en cada país tuvieron una fisonomía distinta. Ateniéndonos a las realidades históricas de España, podemos decir que el Siglo de las Luces, gracias a los hombres ilustrados del reinado de Fernando VI y pese a la incuria del medio siglo anterior, es a mediados de siglo un siglo a medias luces.

François Lopez

Universidad de Burdeos. 